This item was submitted to Loughborough's Research Repository by the author.

Items in Figshare are protected by copyright, with all rights reserved, unless otherwise indicated.

\title{
In with the new: reviewing library induction practices at Loughborough University
}

PLEASE CITE THE PUBLISHED VERSION

PUBLISHER

(C) Emerald

LICENCE

CC BY-NC-ND 4.0

REPOSITORY RECORD

Gadd, Elizabeth A., Max Hunt, Carol Newbold, and Ruth Stubbings. 2019. "In with the New: Reviewing Library Induction Practices at Loughborough University". figshare. https://hdl.handle.net/2134/256. 


\section{Refereed article}

In with the new:

reviewing library

induction practices at

Loughborough University

\author{
Elizabeth Gadd \\ Max Hunt \\ Carol Newbold and \\ Ruth Stubbings
}

\section{The authors}

Elizabeth Gadd is an Academic Librarian and Ruth Stubbings is an Academic Services Manager, both in the Pilkington Library, Max Hunt is Head of Service Delivery in Computing Services and Carol Newbold is a Learning Development Officer, all at Loughborough University, Loughborough, UK.

\section{Keywords}

Libraries, Academic libraries, Induction, Evaluation, Information technology, Skills development

\section{Abstract}

Describes the joint Library, Computing Services, and Learning and Teaching Development induction review at Loughborough University. Considers alternative Higher Education Library induction approaches; assesses recent practice at Loughborough University and describes the new approach adopted. This included a joint induction presentation and associated publication. Other induction methods at Loughborough University Library are also described. Finally, reports on a questionnaire evaluation of the joint induction approach and how it will affect future induction practice.

\section{Electronic access}

The research register for this journal is available at http://www.mcbup.com/research_registers

The current issue and full text archive of this journal is available at http://www.emerald-library.com/ft

\section{Introduction}

In 1995 Loughborough University Library, Computing Services and Flexible Learning Initiative agreed to develop a joint induction presentation for new first year students. The presentations formed part of each academic department's formal induction programme thereby guaranteeing good attendance. Each service would speak for about 15 minutes about how they individually and collectively could support students' learning at university. In 1999 it was agreed that the joint induction process, while thought to be valuable, needed to be reassessed and revitalised. To this end an Induction Review Group was established consisting of a member of staff each from the Library, Computing Services and Learning and Teaching Development (the renamed Flexible Learning Initiative). Their remit was to evaluate the existing induction model, consider alternatives, and implement the chosen option at the beginning of the 2000/ 2001 academic year. This article charts the progress of the group through the review process from a library perspective.

\section{Benchmarking}

One of the first activities of the group was an informal benchmarking exercise. Ideally the previous year's induction presentations would have been evaluated at this point; however, time constraints, and the fact that the group was performing most of the review over the summer vacation when no students were available, made this impossible. Instead, members reviewed the literature, attended seminars, and performed or analysed e-mail surveys on induction practices in other institutions. There were almost as many different induction models as there were institutions. However the group paid particular attention to a number of innovative ideas.

A popular method of library induction is the guided tour. However it has been noted that tours can be time-consuming for staff and dull for students (Abel et al., 1992). Some organisations have therefore remodelled their induction tours. Biffen (1996) describes the implementation of a US-style "round robin" system at the Southampton Institute, where students were conducted round the building to various points where library staff were

(C) Elizabeth Gadd, Max Hunt, Carol Newbold and Ruth Stubbings 
waiting to talk to them. Glasgow Caledonian University library assigned "orientation guides" at the beginning of the 1999/2000 academic year. The guides - who were reshelving staff - "were stationed at various points in [the] main library during core hours and wore badges and carried clipboards to identify themselves" (Crawford, 1999). The guides handled over 1,500 enquiries in two weeks.

The group felt that such models could be successfully adopted in the library, but that they would not extend so easily to Computing Services or Learning and Teaching Development whose services are not so dependent on their buildings. If a three-part tour of the services had been implemented, the main difficulty would have been motivating students to attend. Hathaway has noted that encouraging students to participate in library induction is a particular problem (Hathaway, 1998). Interestingly the solution she implemented at Reading University Library was to incorporate e-mail and Internet access information into the presentation. This increased attendance from 25 to 75 per cent (Hathaway, 2000).

The issue of motivation has been addressed in different ways by other institutions. The Central School of Speech and Drama operates a library quiz with prizes as an induction method (Edwards, 1999). A self-directed workbook is in use at University College Northampton (Rosling, 2000). To motivate students, library cards are only issued on the successful completion of the workbook. At Leicester University Medical School, library induction is an integral and assessed part of the first semester's teaching. There is nothing like a compulsory assessed exercise contributing towards a final year mark to motivate students to apply themselves to library induction! Such measures seem to have worked well in library-only induction settings, and the first two certainly reduced staff input. However, the group was unsure how these ideas would translate to a three-service setting. They were also unhappy about losing face-to-face contact they already had during the induction presentations.

Reducing the burden on staff time at the beginning of semester was a motivating factor behind some other technology-based induction solutions. Huddersfield University has created an interactive learning environment to teach new students information skills. This was created under the auspices of the Huddersfield Information Project (HIP) and as such had project funding (Kaye and Weaver, 2000). University College Northampton has developed a 7-8 minute video that is played to new students (Rosling, 2000). University of Central England undertook such a project a number of years earlier (Abel et al., 1992). Such methods, while innovative, and time-saving once established, could be expensive and timeconsuming to produce. They also lacked the personal contact that group members valued in the current induction presentations.

\section{Reassessing current practice}

Having examined the induction practices at other higher education institutions, and having found nothing that would replace the current model outright, it was decided to re-evaluate the presentations to see how they could be improved. The group brainstormed the subject and came up with the following positive and negative aspects to the presentations:

(1) Positive aspects:

- the presentations reached most students through the timetabled lecture approach;

- they demonstrated an integrated approach to learning support;

- they provided an opportunity for $\mathrm{Q} \& \mathrm{~A}$ on immediate issues;

- they introduced staff personally;

- they featured external subject reviews.

(2) Negative aspects:

- they were too talk based;

- they were too ephemeral information was lost;

- much information was perceived as irrelevant at the time it was given;

- they were not evaluated or tested.

\section{General conclusions}

As new students face large quantities of information at the beginning of their first semester, it was agreed that the aim of the presentations should be to motivate rather than inform. The bulk of our message would be communicated not through the words we 
spoken but through the impression we gave (were we approachable, professional, etc.). For these reasons, the group decided to minimise the number of slides used during the talk to four per service, and to make them mainly image-based. It was felt that facts could best be delivered in hard copy and, to this end, a leaflet would be produced for distribution at each presentation. This would overcome "information-loss" and allow students to refer back to the information when it became more relevant to them. It was agreed that the new format presentation should be evaluated to ensure it was meeting students' needs, and to inform any future developments. Finally, it was felt that the presentations, while providing an essential and timely introduction to the three services, had little lasting value and should not become a "fig-leaf" to obscure the lack of a more systematic induction to IT, information or learning at Loughborough. Each service was therefore encouraged to develop its own training programmes and more detailed induction materials as appropriate.

\section{"Launching in" leaflet}

The production of the joint induction leaflet was felt to be particularly important as it would provide the students with lasting information on the three services. It would also form the backbone of the joint talk. In terms of content, the group tried to envisage what students would need to know at the beginning of term, as opposed to what we might want to tell them. Space was allocated to those topics of most perceived relevance to students rather than being divided three ways between the participating services. The leaflet was made up of a glossy A2 sheet, printed in two colours on both sides, and folded three times down to A5 size. It was entitled "Launching in ... to IT, information and learning at Loughborough", and took an upbeat, "magazine style", using bullet points, boxes, images and quotes[1].

The leaflet contained information on the following topics:

- Where to find help. URLs, e-mail addresses and opening times of the three services were listed, as well as information on how to "use" a URL. A survey performed on the new intake before they arrived at university showed us that while 91 per cent had used the Web before, there remained 9 per cent that had not.
- Passwords, PINs and maps. Students were informed about user names, passwords, and PIN numbers. A map of campus, with the location of the three services, all open access computing laboratories, and study spaces, was given, along with a table detailing the number of PCs, the operating system in use, and the number of group study rooms in each laboratory/ location. This information was not available in any other form and thus proved particularly valuable.

- Getting started with PCs. Segments were dedicated to setting up a networked PC in hall, accessing the campus network remotely, and using e-mail and printing facilities. The back page of the leaflet covered the key points of the university's policy for the acceptable use of IT.

- Finding and using information. Two segments provided information on "getting the best from the Web" and "Web searching strategies" encouraging the use of subject gateways and formulating a successful search. One segment covered the range and format of electronic databases available, and another covered locating printed material via OPAC, borrowing procedures, and loan periods.

- Study skills. One section gave "five keys to effective learning" and another advised on writing skills. The final inner segment covered the learning technologies available at Loughborough including the computer aided learning (CAL) launcher, and the LEARN server, Loughborough's internal Web-based teaching resource.

A total of 4,500 copies of the leaflet were produced. This figure took into account first year undergraduates, taught postgraduates, PGCE students, teaching staff and IT representatives. It was jointly funded by the three participating services.

\section{Joint presentation}

Having designed the leaflet, the group's attention turned to the content of the joint presentations at which the leaflet would be distributed. The presentations were offered by letter to departments, who then booked a slot. A record number of bookings was received with all but one department able to timetable a slot for us. The team also supported a Saturday slot and one that 
finished at $6 \mathrm{p} . \mathrm{m}$. in order to accommodate everyone. Twenty-six presentations were given in total to approximately 2,810 students in 21 departments. While the vast majority of these were undergraduates, some taught postgraduates also attended.

A member of staff from each of the three services attended each presentation. In the library's case, academic librarians gave the presentation to the departments for which they were responsible. This meant that ten academic librarians had to be trained in the new induction format before the beginning of the academic year. One of the three staff members would give an introduction to the session using an OHP slide matching the front cover of the "Launching in" leaflet. Each service would take it in turns to deliver four slides, talking through the aspects of the leaflet that related to them. The group would ideally have liked to use Powerpoint to deliver the slides electronically, but the lack of computing facilities in some lecture theatres meant that the OHP was the "lowest common denominator" available to us.

The library section of the presentation covered:

- the location, opening hours, holdings and core services of the library;

- the newly refurbished entrance to the library where the café and shop were highlighted as well as the start of the self-guided tour (SGT);

- where students could find help either through information desks, "ULISEES" our electronic enquiry service, information skills training sessions or the library Web pages;

- how to use the library for a first assignment: reading lists, OPAC, loan periods, the Short Loan Collection and the availability of PCs in the library.

\section{Other library induction activities}

To complement the joint induction sessions the library provided a range of other introductory services. These included the self-guided tour, a range of library leaflets, orientation guides and tailored information skills sessions [2].

In 1992 the library's Information Skills Training (IST) group developed an SGT. It comprises a leaflet, explanation boards and numbers hanging from the ceiling situated round the library. The SGT leaflet contains floor plans of each level of the library with important services such as photocopiers and group study rooms marked on them. It also contains numbers on the floor plans that correspond to the numbers hanging from the ceiling of the library, so that borrowers can ascertain where they are on any particular floor, and brief explanations of the services available. The explanation boards are located next to particular services and provide more in-depth information than can be included in the SGT leaflet. A total of 6,000 leaflets are printed each year and there are normally few stocks left. The SGT leaflets are not handed out in the joint induction sessions; instead students are encouraged to collect them from the library when they plan to undertake the tour. A few programmes book a time slot for their students to undertake the SGT. The SGT is amended as appropriate each year and at present is undergoing a major review with the help from students of the Department of Information Science.

The library's Publications Group has produced a brand new range of leaflets that outline library services[3]. These include a general guide to the library, The Library Uncovered [4] and two leaflets targeted at specific readers, Part Time and Distance Learners and External Readers and Visitors[3]. The new style leaflets are different from the previous series, in terms of both image and content. Bright colours and pictures have been utilized, but only two colours have been used in printing, therefore they are inexpensive to produce. We have also tried to provide readers with information they want, rather than what we would like to tell them; for example, the Part Time and Distance Learners leaflet gives step-by-step instructions on how to use the postal book service. Again these leaflets are not handed out at the joint induction sessions because they relate just to the library and we do not wish to overload the students with documentation. They are available from display stands on each level of the library and are used in some of the information skills training sessions that the library delivers. Anecdotal evidence suggests that the new guides are popular and they vanish from the display stands quickly. The Publications Group will be formally evaluating the new leaflets during the spring of 2001 .

The IST group was impressed with the outcomes of the "orientation guides" used at Glasgow Caledonian University. 
Unfortunately, the library did not have the resources to employ the shelvers as "orientation guides" alone. But the shelvers did agree to wear large badges saying "Welcome, can I help you?" as well as their university ID badges and to offer assistance to students who appeared to be lost when they were shelving the book stock. During the first four weeks of term, the shelvers answered 366 queries, 347 of which where directional queries. A total of 19 queries were referred to the information desks. Most queries related to discovering where particular sections were in the library, such as short loan and queries relating to not being able to find particular books or journals on the shelves. Other queries related to how many books could be borrowed, booking study carrels and help with OPAC. We have been unable to quantify whether the shelvers were asked more questions than in previous years, as this information had not been recorded before. However, the shelvers felt that they have answered more questions.

Academic librarians offer information skills training to their departments. Take-up varies, but some departments request combined induction and information skills training. This is particularly prevalent with foundation and taught postgraduate courses. A prime example of this is a twohour session delivered to MA students in the business school, where library services and literature searching techniques are discussed. Another example is the training sessions offered to 250 art foundation students in September of each year. The students visit the library in groups of 50 . They are divided into two smaller groups and while one group is given a talk on the library and how to use OPAC the other group undertakes the SGT. The groups swap over. They then have hands-on activities relating to OPAC and the work they undertake feeds into a formal assignment which is marked by academic staff.

Evaluation of the joint induction method In December, two months after the joint induction, the group designed a questionnaire to solicit students' views on the presentation and the leaflet. The questionnaire was mounted on the Web and advertised on the Student E-mail Bulletin board. Small prizes were on offer to respondents chosen at random. The questionnaire covered the following areas:

- how useful they found the presentation;

- whether it was held at an appropriate time;

- whether the level of detail was about right;

- how useful they found the leaflet;

- what else they would like to be included on the leaflet;

- how important particular skills were to them;

- which skills they would expect to improve at university;

- how confident they felt in particular IT skill areas.

A total of 143 students completed the questionnaire. This represented about 5 per cent of the total first year undergraduate population. Of those who gave their gender 58 per cent were male and 42 per cent female. Across disciplines, 47 per cent were social science/humanities students, 28 per cent were engineers, and 25 per cent were from the science faculty. Of the respondents, 91 per cent had attended an induction presentation. One result of the questionnaire being mounted on the Web and advertised by e-mail was a heavy bias of networked IT users within the sample.

Overall, responses were very positive about the presentation. Of those that attended, 96 per cent found it useful or very useful, leaving just 4 per cent that had not. About three-quarters (73 per cent) of those who did not attend the induction presentation felt that such a session would have been useful or very useful.

The timing was also felt to be right, with 85 per cent saying they thought it was held at a good time. In terms of detail, 86 per cent thought that the level of detail was "about right", 7 per cent thought the session went into "too much" detail, and the other 7 per cent thought there was "too little".

When asked about the level of detail provided about each learning support area, most students felt there was "enough". However 21 per cent said there was too little IT, 25 per cent said there was too little information skills coverage and just over 30 per cent wanted more study skills information. 
The leaflet, distributed with the talk, was thought useful or very useful by 84 per cent of respondents. When asked what was lacking in the leaflet several respondents asked for the following:

- more information about the networked hall service;

- access codes for 24 hour laboratories and opening times (though the latter were in the leaflet);

- where to find books/periodicals for specific subjects.

A series of questions were posed in order to assess how students perceived their own IT, information and learning skills. It was hoped that the responses could influence the production of service-specific induction training programmes and materials, as well as future incarnations of the joint induction approach. Students were first asked to state how important certain skill areas were for them on a five-point scale ranging from "very important" through to "not at all important". Figure 1 illustrates the percentage of students rating each area as either important or very important.

It can be seen that IT and writing skills were considered the most important to students with 90 per cent rating them highly, followed by information skills (finding and using information). Of least importance appeared to be numeracy and group working skills. Engineers scored consistently higher ratings for the importance of all the above, except for writing, where importance was rated broadly similar to other faculties.

The next question asked how students expected their skills to improve as a result of their degree. Figure 2 illustrates the responses. It can be seen that there is some correlation between the skills they considered important and those they expected to improve. Information and IT skills were two examples. At the other end of the scale, numeracy was considered relatively unimportant and few expected to improve in this area. As was anticipated, there were variations between the faculties as to expectation of improvement. For example, although overall 52 per cent of students expected their numeracy to improve, within faculties 65 per cent of engineering students expected to improve, but only 42 per cent of social sciences and humanities students.

Apart from this example, the variation between faculties was never greater than 15 per cent and was usually about 10 per cent.

Two further questions asked students to select the one skill they thought needed most improvement, and the one they thought required the least improvement. This produced some interesting results (Figure 3). It was thought that one set of results might be a reverse correlation of the other. However, although this was virtually the case in five of the subject areas (i.e. the largest proportion of students stated that their presentation skills needed most improving, and the smallest

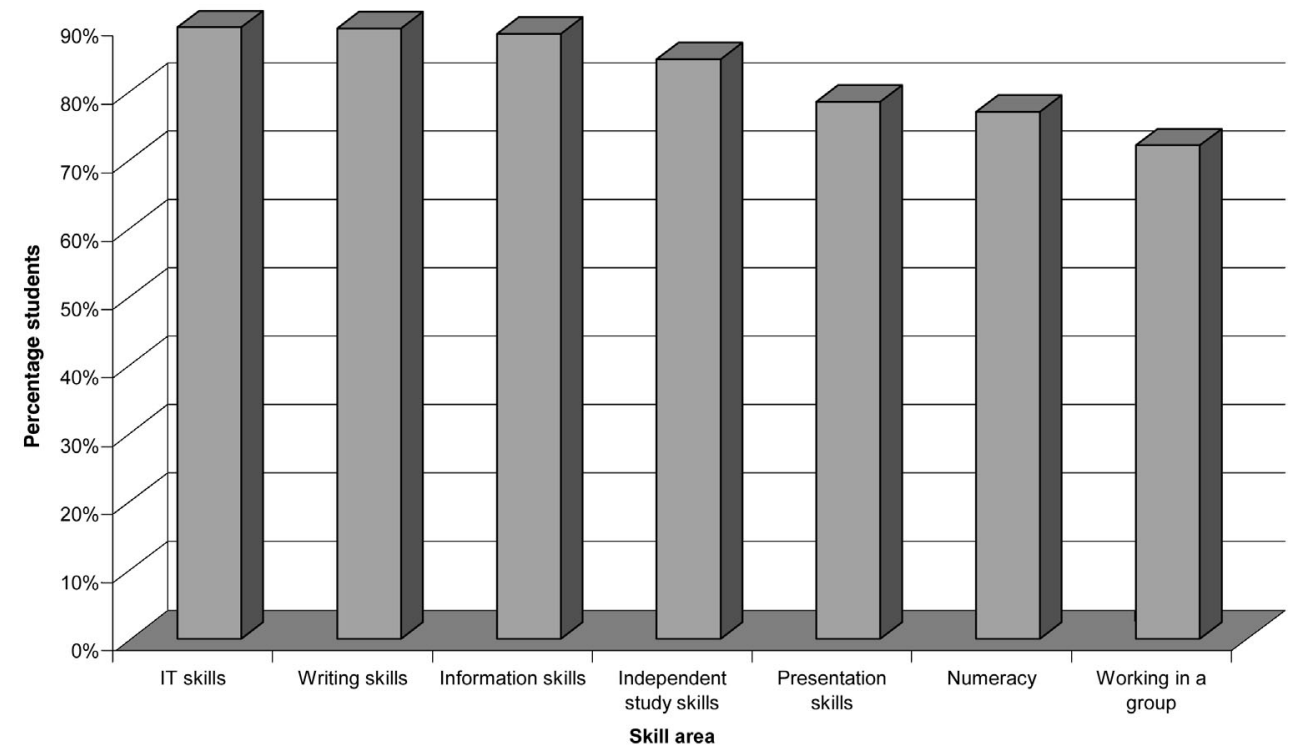


Figure 2 Where students expect to improve

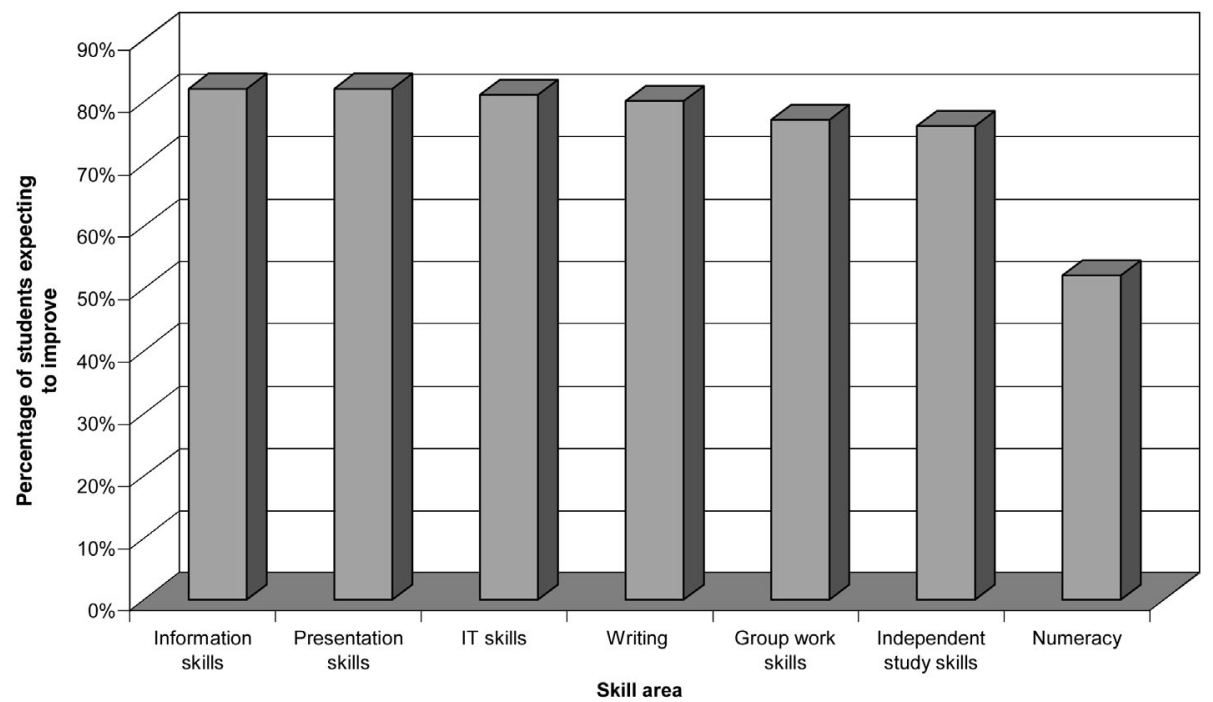

Figure 3 Skills for improvement

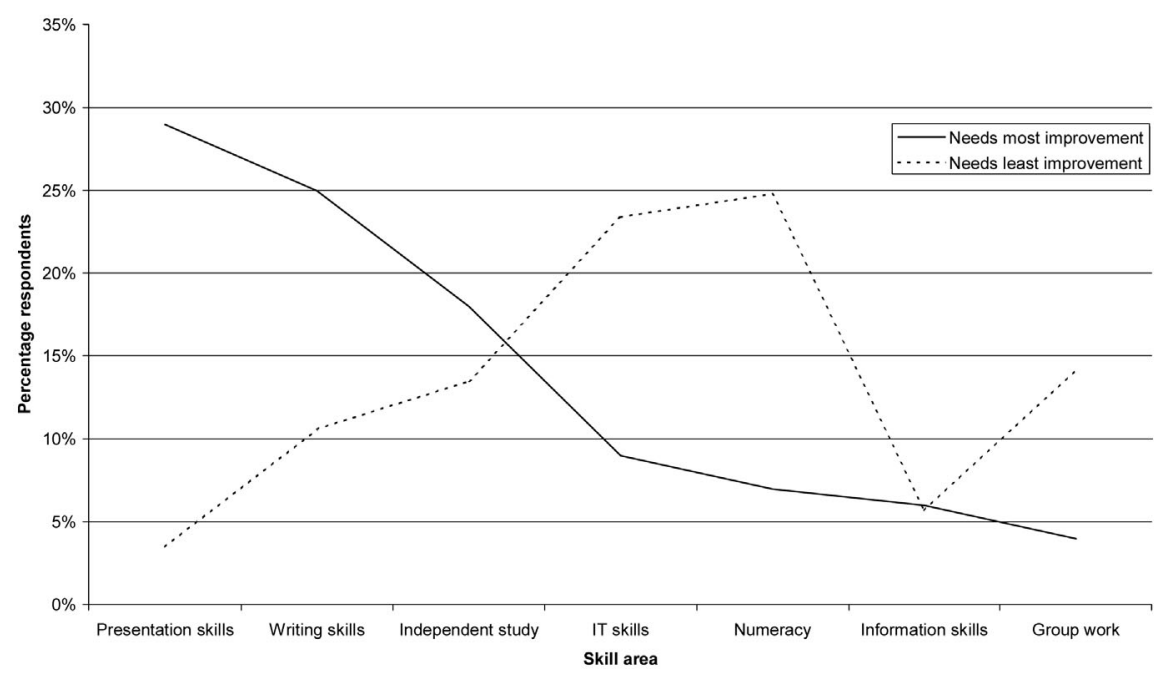

group thought their presentation skills needed the least improvement), information skills and group work were an exception. Only 6.4 per cent of respondents thought their information skills needed the most improvement, and yet just 5.7 per cent thought they needed the least improvement. Bearing in mind that information skills was the area in which most students expected to improve, this result is, at first glance, confusing. One interpretation is that while students know their information skills need improving, they expect them to improve as a natural outcome of their degree, and would not consider working on them as an act of self-improvement.

\section{Summary conclusions}

Summary conclusions from the evaluation exercise were drawn as follows:

- The induction presentation and leaflet is a highly useful intervention in the student's first week.

- The timing and content of the presentation was felt to be appropriate.

- Students expect their information skills to improve while at university, but might need more encouragement to take a proactive approach to improvement.

- IT skills are considered very important to students and they expect to improve in this area while at university. However, 
they recognise that it is their study skills that need the most improvement.

- Students rate presentation, independent study and writing skills very highly.

The evaluation provided valuable feedback that will allow the group to fine-tune the induction for next year's intake. Overall the exercise has proved enlightening and beneficial, both in terms of the greater integration of learning support services on campus, and most importantly, launching students into a successful learning experience at Loughborough.

\section{Notes}

1 The "Launching in" guide is available online at: http://www.lboro.ac.uk/library/launching.pdf (accessed 16 May 2001).

2 Our SGT is available at: http://www.lboro.ac.uk/ library/tour.pdf (accessed 16 May 2001).

3 All the Library's publications are listed online at: http://www.lboro.ac.uk/library/pubs.html (accessed 16 May 2001).

4 The Library Uncovered guide is available online at: http://www.lboro.ac.uk/library/uncovered.pdf (accessed 16 May 2001).

\section{References}

Abel, M. et al. (1992), "The design and production of a multimedia presentation for library induction", British Journal of Academic Librarianship, Vol. 7 No. 2, pp. 91-100.

Biffen, K. (1996), "Inductions: student tours USA fashion", Library Association Record, Vol. 98 No. 1, pp. 30-1.

Crawford, J. (1999), "Orientation guides", e-mail to Lis-link discussion list, Wednesday 27 October.

Edwards, J.A. (1999) "Re: dumbing down - use a quiz", e-mail to Lis-link discussion group, Thursday 23 September, 1999.

Hathaway, H. (1998), "Freshers' induction at Reading", SCONUL Newsletter, Vol. 13, Spring, pp. 10-13.

Hathaway, H. (2000), "Another brick in the wall? A lighter touch to Freshers' induction", unpublished paper presented at the UC\&R East Midlands seminar, Library induction - can we ever get it right?, Loughborough University, 26 January.

Kaye, J. and Weaver, M. (2000), "Huddersfield Information Project (HIP): helping new students learn information searching skills", unpublished paper presented at the UC\&R East Midlands seminar, Library induction - can we ever get it right?, Loughborough University, 26 January.

Rosling, A. (2000), "Text, vibes and videotapes: large group Library induction during freshers' week at UCN", unpublished paper presented at the UC\&R East Midlands seminar, Library induction - can we ever get it right?, Loughborough University, 26 January. 